\title{
Capacity building for hydrological change - using a blended learning approach
}

\section{HERIBERT NACKEN}

RWTH Aachen University, UNESCO Chair in Hydrological Change and Water Resources Management, Mies-van-der-Rohe Straße 17, D-52074 Aachen, Germany

nacken@lfi.rwth-aachen.de

\begin{abstract}
Extreme hydrological events have always been a challenge to societies. There is growing evidence that hydrological extremes have already become more severe in some regions. The Middle East and North Africa (MENA) region is characterized as one of the world's most water-scarce and driest regions, with a high dependency on climate-sensitive agriculture. There is an urgent need for capacity building programmes that prepare water professionals and communities to deal with the expected hydrological changes and extremes. The most successful capacity building programmes are the country driven ones which involve a wide range of national stakeholders, have a high degree of in-country ownership and have an applicability character. The method of choice to set up such capacity building programmes will be through blended learning.
\end{abstract}

\section{WATER SCARCITY IN THE MENA REGION}

Since the mid-1990s, Integrated Water Resource Management (IWRM) has been targeted by national and international water organisations and water politics. The second UN World Water Development Report (UNESCO WWAP 2006a) states that sharing the water resources and ensuring their sustainability at the same time will be our problem of the future.

"There is enough water for everyone. The problem we face today is largely one of governments: equitably sharing this water while ensuring the sustainability of natural ecosystems" (UNESCO WWAP 2006b).

Is it really true that there is enough water for everyone in the MENA (Middle East and North Africa region? Let us have a closer look at the facts and figures. All in all, water seems to be an unlimited resource for John Q. Public when it comes to the 1.4 billion $\mathrm{km}^{3}$ of water that our Earth is supplying us with. But, $97.5 \%$ of this amount is salt water and can only be made available for human beings through the use of high energy processes (e.g. desalination).

Most of the remaining $2.5 \%$ of freshwater on our Earth is stored in glaciers and perpetual ice so that in the long run there are just $14000 \mathrm{~km}^{3}$ that we can make use of (some hydrologists only take a total budget of $9000 \mathrm{~km}^{3}$ into account when it comes to integrated water resource management for mankind). So, out of each 100000 litres of water only 1 litre can be used for public water supply, food production and industry.

John Q. Public might think that this is still a reasonable amount of water to supply his private needs, but what he normally is not aware of is the distribution of water between the different uses. Worldwide $67 \%$ of the usable water resources are linked to food production in farming and agriculture; $19 \%$ are linked to the industrial sector and 5\% are linked to evaporation from large dams and reservoirs. So, on a worldwide scale only $9 \%$ of the freshwater resources are linked to private supply.

For the MENA region there is even an additional tightening; about 5\% of the world population live in the MENA region and have to share a water budget that only sums up to $1 \%$ of the worldwide freshwater resources. So we need to take a closer look at the available water resources for each and every person, and the hydrological changes that have already appeared.

The benchmark for this is the internal renewable water resource per capita and year $\left(\mathrm{m}^{3} / \mathrm{cap} /\right.$ annum). Figure 1 provides a worldwide overview of these renewable water resources, based on the data of 1995 (UNESCO WWAP 2003). Through this, regions under water stress or water scarcity can be identified. The Food and Agriculture Organization (FAO) of the United Nations regards water as the major civil constraint to socio-economic development and environmental protection at levels of internal renewable water availability of less than $1000 \mathrm{~m}^{3} / \mathrm{capita}$. At present, the Oman has a rate of $388 \mathrm{~m}^{3} / \mathrm{cap} / \mathrm{annum}$, so Oman's integrated water resource 


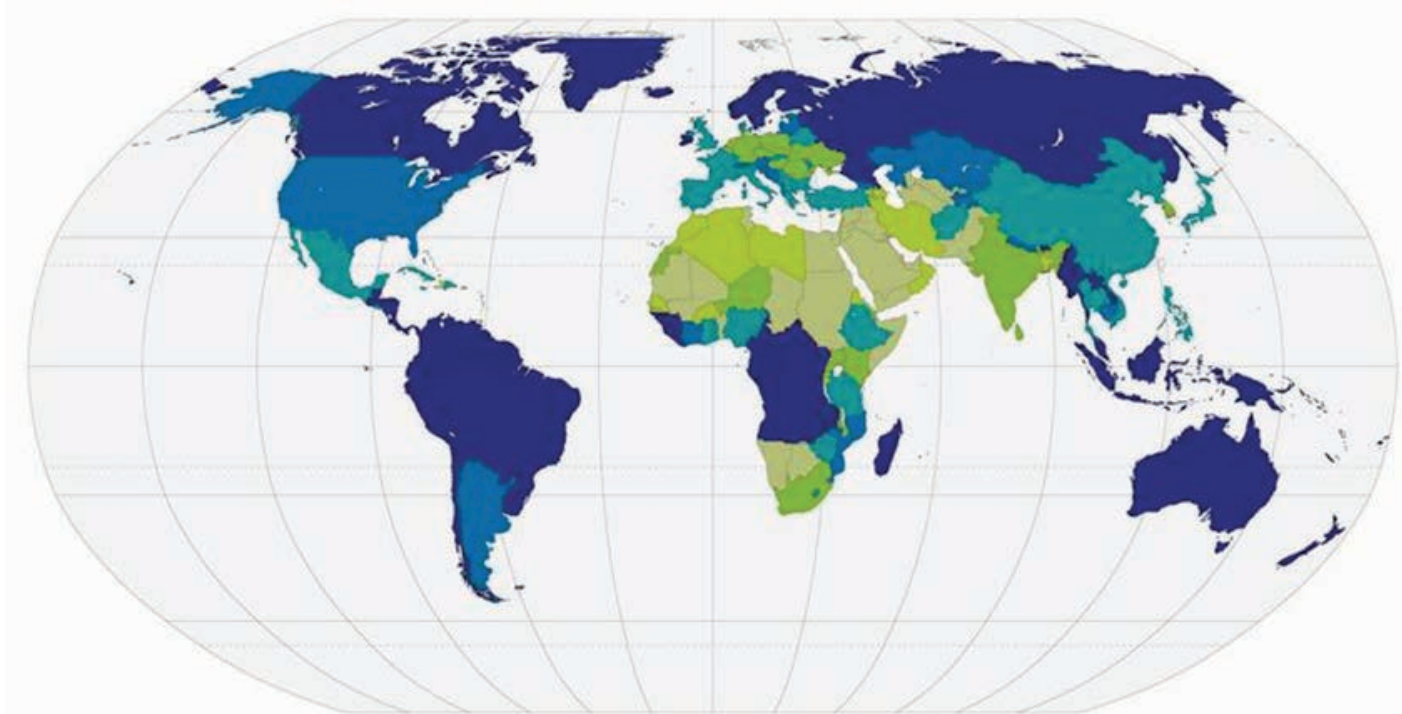

Map II.1. Internal renewable water resources generated within a country on a per capita basis, circa 1995 [m³/cap/annum]

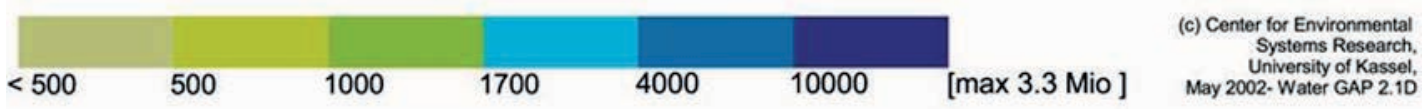

Fig. 1 Worldwide internal renewable water resources.

management is facing a severe problem of water scarcity. This is not only a problem for Oman but for the whole MENA region, as stated at the Fourth World Water Forum in 2006:

"The region is the most arid region in the world. Of the total area of about 14 million $\mathrm{km}^{2}$, more than $87 \%$, is desert. Except for coastal strips in the Maghreb and the East Mediterranean, and the mountains of Northern Iraq and the Arabian peninsula, conditions are predominantly arid to hyper arid. Water resources are consequently very sparse. Total renewable water resources in the region are estimated at about $335 \mathrm{~km}^{3} /$ year, with demand already exceeding $200 \mathrm{~km}^{3} /$ year (about $60 \%$ of the renewable resource) and rising fast" (Fourth World Water Forum 2006).

As the world population is still increasing (see Fig. 2) and worldwide production is still on the rise (with non-sustainable consumption patterns), integrated water resource management will face severe circumstances within the next decades.

The first UN World Water Development Report (Water for People, Water for Life) indicated that by 2050 at least two billion people in 48 countries will suffer water scarcity, and this might even run up to a number of seven billion people in 60 countries. So the MENA region is facing physical as well as economic water scarcity in the near future, as seen in Fig. 3.

By no means can we change these physical constraints. So we will have to focus very much on teaching and training of sustainable ways of water use and management in the process of capacity building related to the hydrological change and water management.

The United Nations Development Programme (UNDP) defines capacity and capacity development as follows:

"Capacity is the ability of individuals, institutions and societies to perform functions, solve problems, and set and achieve objectives in a sustainable manner. Capacity Development (CD) is thereby the process through which individuals, organisations and societies obtain, strengthen and maintain the capabilities to set and achieve their own development objectives over time." (see http://www.capacity.undp.org/)

This capacity building will be very much based on knowledge transfer from specialists to dedicated members of water-related organizations as well as to the wider public. A targeted approach to enhance this process of knowledge transfer makes use of eLearning and blended learning concepts. 


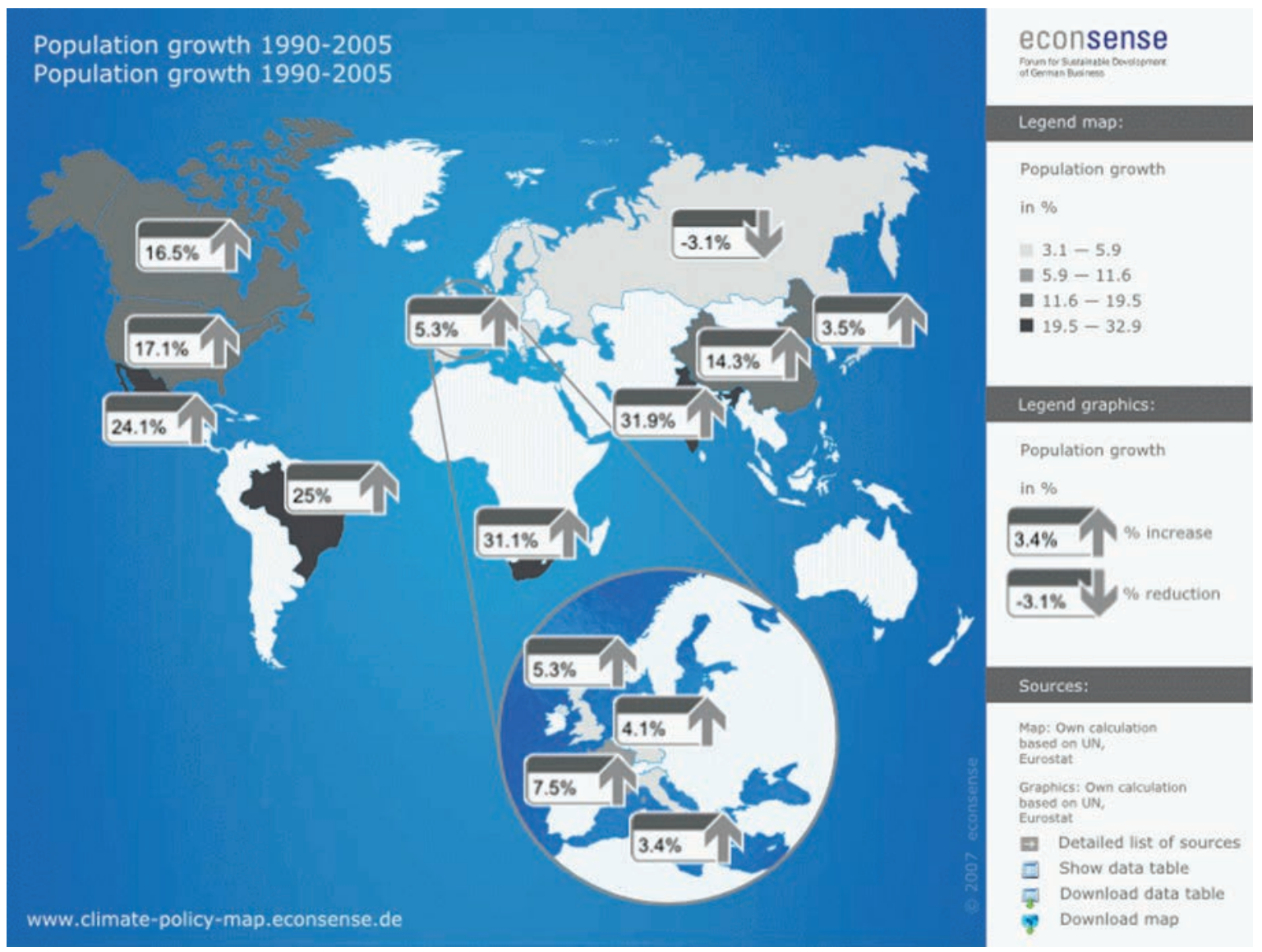

Fig. 2 Worldwide population growth by regions in \%.

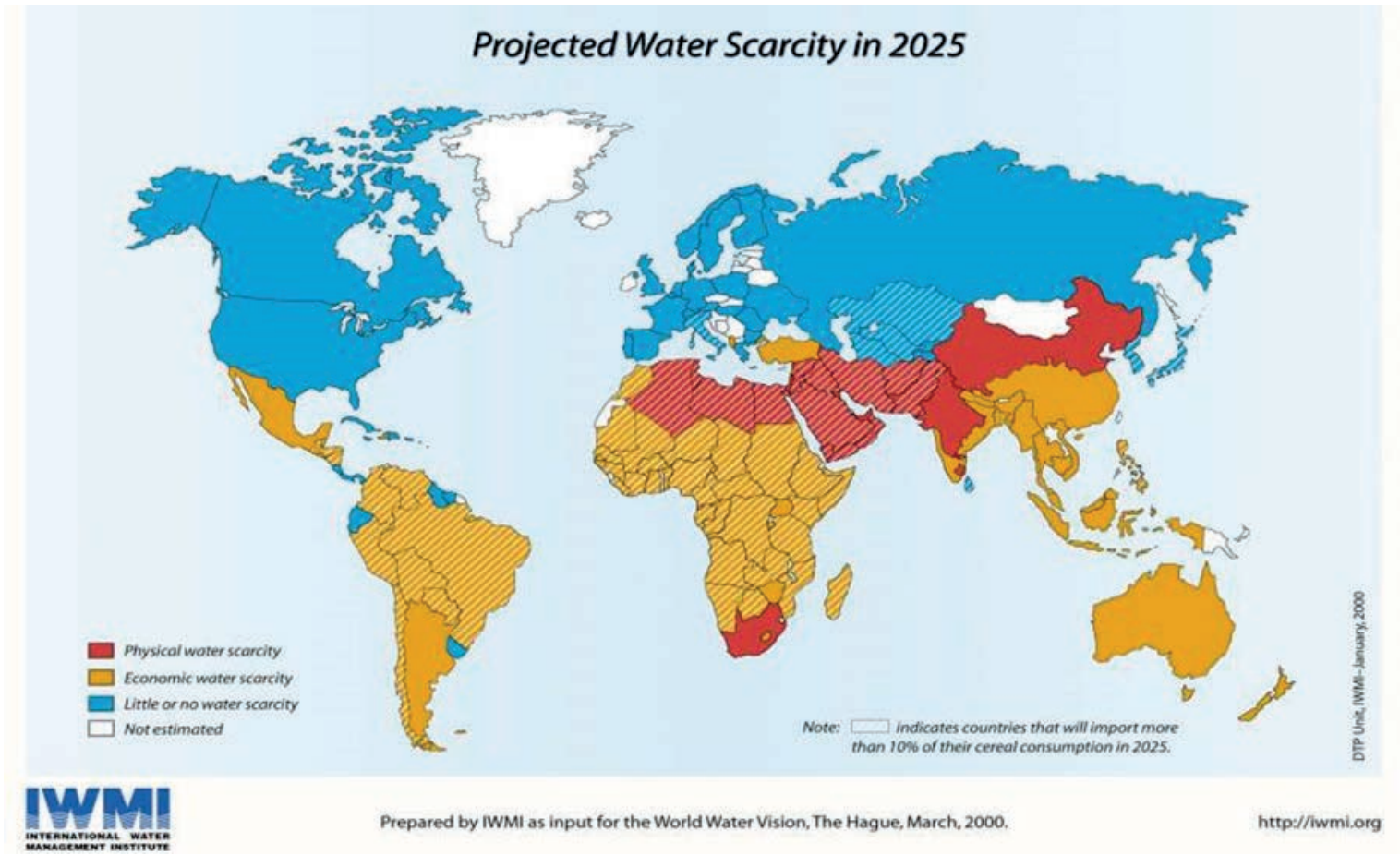

Fig. 3 Projected water scarcity in 2015, worldwide by country. 


\section{CAPACITY BUILDING AND KNOWLEDGE TRANSFER THROUGH ELEARNING}

Focusing on a targeted knowledge transfer (either traditional instructor-led courses or pure eLearning courses), you have to be aware of the fundamentals of the Selection-OrganizationIntegration theory (also called SOI theory). The fundamentals of the theoretical SOI model are:

- human knowledge processing strictly separates between aural and visual inputs (two separate channels for information entry);

- the processing capacity of those two input channels and the short-term memory is limited (the magic seven);

- learning is always an active process; we have to develop a coherent mental model (or reproduction) of the learning objects.

Those interested in getting to know more about these theoretical approaches should look at Sweller and Chandler (1991) as well as Paas (2003). The learning process really is labour (in our German language the word labour has its origin in hardship, so eLearning has nothing to do with entertaining people, as so many people believe).

To discover more about the concept of eLearning and the blended learning approach you can visit the URL nordsee.lfi.rwth-aachen.de/basics/. There you will find a taped eLecture that will explain the concept in detail (it takes some 26 minutes to follow).

\section{SOME PRINCIPLES OF MULTIMEDIA-BASED LEARNING}

Based on the assumptions of the SOI theory, Clark and Mayer (2002) developed six principles that should be obeyed during the conception and creation of multimedia content. Because these principles are easy to understand, they are mentioned without any further explanation:

multimedia principle

modality principle

continuity principle

redundancy principle

coherence principle

personalization principle a combination of text and diagrams/illustrations is more effective as a method of knowledge transfer than text only

explanations and descriptions, dedicated to illustrations and diagrams are better grasped in spoken form (aural) than in written presentation

text information and diagrams that refer to each other are to be presented interrelated

the learning process is negatively influenced when knowledge contents are presented in written and spoken form simultaneously (q.v. Dual Code Theory by Paivio)

media elements are to be used targeted and economically (thrifty); an overkill will have negative consequences for the learning process

expert sociolects should be avoided; in general, comprehensible explanations enhance and enrich the learning effect

Based on the SOI theory and these principles of multimedia-based learning, I always try to design my courses in a manner that about $80 \%$ of the information I would like to transform into knowledge is presented in an aural way (independently of setting up a classical face-to-face or a pure eLearning module). Animated graphs, flash files or video sequences will fill the residual part.

\section{ELEARNING DESIGN PATTERN}

When it comes to the blueprint of eLearning courses, there are often discussions about the right technology approach. So we should focus on the didactical structure of eLearning courses and the design patterns. The structure that we are using in the design of eLearning courses is a three-step approach (see Fig. 4). 


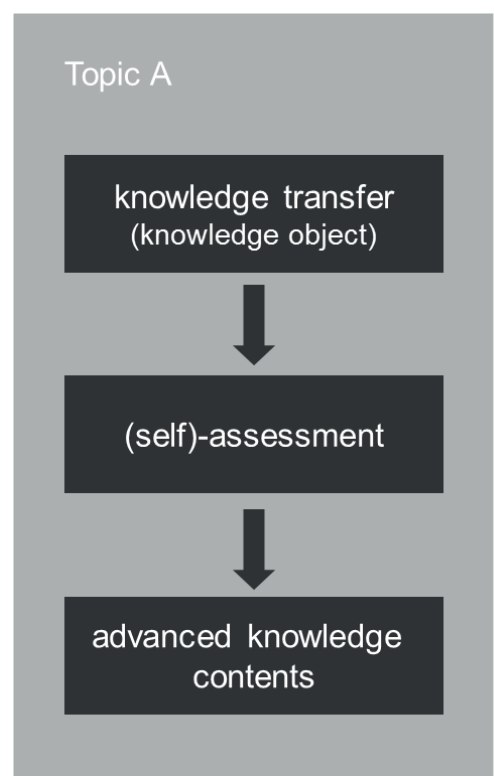

Step 1 [mandatory]

Step 2 [mandatory]

Step 3 [optional]

Fig. 4 Three-step approach to the design of an eLearning course.

You should start by unitizing the content into well-defined topics. Within each topic, the first step will be a knowledge transfer which is realized by so-called knowledge objects. These knowledge objects could be your aural presentations, videotaped lectures or webinars. A knowledge object has the task to transfer all the necessary information to the attendee. Again, one should be aware of dual coding all the information. If you stick to the assumption that your knowledge transfer is realized primarily by aural coding, sequences should not be longer than approximately five minutes (the reason for that is that attendees will lose their attention after a while when looking at a monitor where hardly anything is visually changing). If for the knowledge transfer it is necessary to have longer sequences, you should add a video stream of the speaker which the attendee can visually concentrate and focus on.

The second step of the didactical structure will be an assessment. With that the attendee can really prove whether the knowledge transfer has been successful and he or she did acquire the knowledge, skills and competencies that the first step allocated. Most often this step is done in the form of a quiz (using true-false, single-choice, multiple-choice, short answer, numerical or matching questions). Best practice will be the use of the Question and Test Interoperability Specification (IMS QTI) standard; see www.imsproject.org/question). The assessment (as well as the knowledge transfer) should be designed in such a way that it motivates, incentivizes and encourages the attendees. Moreover, the design of the eLearning module should take into account the fact that giving learners more than one method to solve a problem, or showing them multiple approaches to solve a task, will greatly increase the efficiency and the impact of your knowledge transfer.

The first two steps are always mandatory, whereas step three is optional and will offer additional, advanced knowledge content to the attendees. This can be any further information on the selected topic, a series of links to internet pages with topic-related information, or any other add-on.

You can easily link different topics (steps 1-3) in a linear chain, where every topic has to be followed one after the other (often called a programme flow model). Another possible design pattern would be the presentation of these topics and offering of different entry points for the attendees (so that they can choose which contents they would like to follow). If you choose this design pattern, it could be a good idea to start each topic with an assessment to find out whether the attendee knows all the basics necessary for this topic. Depending on the result of the assessment, the attendee will be allowed to go on with a topic, or will possibly be redirected to the topic he needs to repeat before starting the new subject. 
When you check the internet for eLearning modules that are well designed and targeted, you will find brilliant courses for hydrology and water resource management. Just to give you one idea, I would like to mention COMET (www.comet.ucar.edu). The material they designed (with a team of up to 37 people) is free of charge and may be implemented in any learning management system.

\section{WHAT IS STILL MISSING ON THE AGENDA}

For the time being the situation concerning eLearning content and courses is very promising; but there are still some things that are missing.

\subsection{Proper and joint pedagogical design patterns}

Technology and software solutions really help us a lot while designing and running eLearning courses, but the quality of the eLearning courses and content is dependent on and related much more to the pedagogical design patterns. As for me, I do consider this part as the weakest link in the chain for the time being.

\subsection{Knowledge objects, really compatible to existing standards}

The future of eLearning will be blended learning, as a blend of traditional instructor-led courses plus additional pure self-directed eLearning courses (Fig. 5). To make this happen there is definitely a condition needed whereby the content designers fulfil the requirements of existing eLearning standards. These standards still have to evolve, but it would be a benefit for the eLearning community if only SCORM (see www.adlnet.gov) was supplied by all content designers to exchange and blend eLearning modules between different learning management systems.

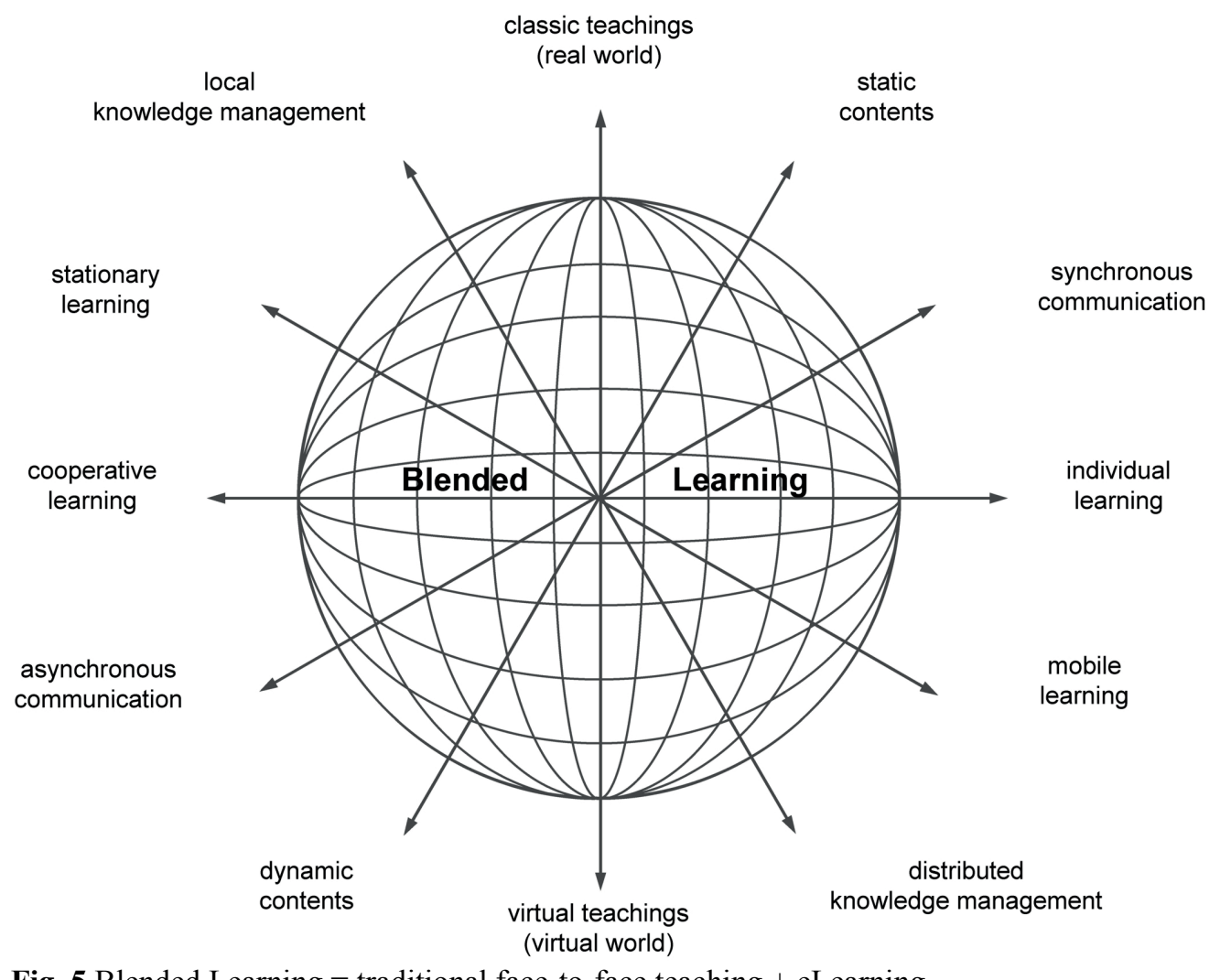

Fig. 5 Blended Learning $=$ traditional face-to-face teaching + eLearning. 


\subsection{A non-commercial eLearning stock exchange}

Imagine you are a content designer for water resource management and wish to set up a working group with four experts, belonging to different institutes. All of you would like to design eLearning courses on a big scale and with really impressive quality. So why not collaborate, agree on common design patterns and realize eLearning content in accordance with existing eLearning standards (SCORM and QTI). Thereby you could, for example, concentrate on the design of knowledge objects and assessments for the water cycle and by the end of your design, you would have not just one high quality module but five.

You could organize this exchange of eLearning content in either a commercial or a noncommercial way (as we are trying at German universities). This would greatly reduce the amount of money spent for redundant content, promote the idea of using eLearning courses and help focus content designers on what they are really good at.

\subsection{Benchmarking eLearning content}

At present there is no reliable system to compare different eLearning content. Whenever you would like to use content that you did not design yourself it is up to you to test and grade it. It would be of great help if there was such a thing as a benchmarking system for media-enriched content. Although there are benchmarking systems that can handle this task, there is a lack of content that is designed in accordance with the Learning Object Module (as part of the SCORM standard). Without the metadata information described in this standard it is not possible to set up the fundamentals of benchmarking. Talking about sustainable content for capacity building in the theme of hydrological change, there will be a great need for such benchmarking.

As mentioned above, the future of capacity building through eLearning looks bright and promising; we do have the tools and technologies to support us and we know the design patterns. It is just up to us to make the best of it.

\section{REFERENCES}

Clark, R.C. and Mayer, R.E. (2002) E-Learning and the Science of Instruction. Proven Guidelines for Consumers and Designers of Multimedia Learning. Jossey-Bass/Pfeiffer.

Fourth World Water Forum (2006) Capacity building in the MENA Region, Ministerial Panel-INWENT/AWC, In: Final Report of the 4th World Water Forum, National Water Commission of Mexico 2006, www.worldwatercouncil.org

Miller, G.A. (1956) The magical number seven, plus or minus two: Some limits on our capacity for processing information. Psychological Review 63, 81-97.

Paas, F., Renkl, A. and Sweller, J. (2003) Cognitive load theory and instructional design: Recent developments. Educational Psychologist 38(1), 1-4.

Paivio, A. (1986) Mental Representations: A Dual-Coding Approach. Oxford University Press.

Simon, H. A. (1974) How big is a chunk? Science 183, 482-488.

Sweller, J. and Chandler, P. (1991) Evidence for cognitive load theory. Cognition and Instruction 8(4), 351-362.

UNESCO WWAP (2003) UNESCO World Water Assessment Programme, Water for People, Water for Life - World Water Development Report 1, UNESCO/Berghahn Books 2006, www.unesco.org/water/wwap

UNESCO WWAP (2006a) UNESCO World Water Assessment Programme, Water a Shared Responsibility - World Water Development Report 2, UNESCO/Berghahn Books 2006, www.unesco.org/water/wwap

UNESCO WWAP (2006b) UNESCO World Water Assessment Programme World Water Development Report 2 - Executive Summary, UNESCO/Berghahn Books 2006, www.unesco.org/water/wwap 